\title{
Selective Production of Green Hydrocarbons from the Hydrotreatment of Waste Coconut Oil over Ni- and NiMo- supported on Amine-functionalized Mesoporous Silica
}

\author{
Wega Trisunaryanti, Savitri Larasati*, T. Triyono, Nugroho Raka Santoso, \\ Cahyarani Paramesti
}

Department of Chemistry, Universitas Gadjah Mada, Yogyakarta, Indonesia.

Received: 26 th January 2020; Revised: $13^{\text {rd }}$ May 2020; Accepted: $13^{\text {rd }}$ May 2020; Available online: 30th July 2020; Published regularly: August 2020

\begin{abstract}
In order to overcome the depletion of energy resources, the production of fuel from a renewable source (green fuel) has aroused attention. The present work serves as a comparative study for green fuel production by utilizing monometallic $\mathrm{Ni}$ and bimetallic NiMo loaded on amine-functionalized mesoporous silica (MS). Two types of catalysts, denoted as $\mathrm{Ni} / \mathrm{NH}_{2}-\mathrm{MS}$ and $\mathrm{NiMo} / \mathrm{NH}_{2}-\mathrm{MS}$, were prepared and evaluated for its catalytic activity in the hydrotreatment of waste coconut oil (WCO) at $450{ }^{\circ} \mathrm{C}$ under the flow of $\mathrm{H}_{2}$ gas $\left(20 \mathrm{~mL} \cdot \mathrm{min}^{-1}\right)$. Each catalysts were characterized by using X-ray Diffraction (XRD), Atomic Absorption Spectrometer (AAS), Transmission Electron Microscopy (TEM), Scanning Electron Microscopy (SEM), and Fourier Transform Infra Red (FTIR). Study of selectivity by GC-MS showed that gasoline-range hydrocarbon, especially n-undecane, was the major compound in the liquid products generated by the two amine-functionalized catalysts prepared in this study. The result showed that monometallic $\mathrm{Ni} / \mathrm{NH}_{2}-\mathrm{MS}$ with surface area, total pore volume, nickel loading and average pore diameter $328.68 \mathrm{~m}^{2} \cdot \mathrm{g}^{-1}, 0.25 \mathrm{~cm}^{3} \cdot \mathrm{g}^{-1}, 1.90 \mathrm{wt} \%, 3.10 \mathrm{~nm}$, respectively, exhibited the best performance in producing liquid hydrocarbon and generated higher level of liquid product (77.9 wt\%) than bimetallic NiMo/ $\mathrm{NH}_{2}$-MS $(76.3 \mathrm{wt} \%)$. However, it is highlighted that adding $1.08 \mathrm{wt} \%$ of Mo in bimetallic $\mathrm{NiMo} / \mathrm{NH}_{2}$-MS comprising $0.83 \mathrm{wt} \%$ of $\mathrm{Ni}$ improved the catalyst selectivity towards producing higher level of gasoline-range hydrocarbon (43 wt\%). The bimetallic $\mathrm{NiMo} / \mathrm{NH}_{2}-\mathrm{MS}$ prepared was found to have surface area, total pore volume, and average pore diameter of $325.13 \mathrm{~m}^{2} \cdot \mathrm{g}^{-1}, 0.14$ $\mathrm{cm}^{3} \cdot \mathrm{g}^{-1}, 3.22 \mathrm{~nm}$, respectively. Copyright (C) 2020 BCREC Group. All rights reserved
\end{abstract}

Keywords: hydrotreatment; biofuel production; amine-functionalized; bimetallic catalyst; mesoporous silica

How to Cite: Trisunaryanti, W., Larasati, S., Triyono, T., Santoso, N.R., Paramesti, C. (2020). Selective Production of Green Hydrocarbons from the Hydrotreatment of Waste Coconut Oil over Ni- and NiMo-supported on Amine-functionalized Mesoporous Silica. Bulletin of Chemical Reaction Engineering \& Catalysis, 15(2), 415-431 (doi:10.9767/bcrec.15.2.7136.415-431)

Permalink/DOI: https://doi.org/10.9767/bcrec.15.2.7136.415-431

\section{Introduction}

The main energy resources that have been used globally come from fossil fuels such as

* Corresponding Author.

E-mail: savitri.larasati@mail.ugm.ac.id (S. Larasati);

Telp: +62-856-40704163 petroleum oil, coal, and natural gas as they can be burned to produce a significant amount of energy [1]. However, the disproportion between the high energy demand and the limited stock of fossil fuel as a non-renewable energy source becomes a major problem the world is facing today. In order to overcome the depletion of energy resources, the production of fuel from a 
renewable source (green fuel) has aroused many attentions.

In recent years, hydroprocessing of edible and non-edible vegetable oil in the production of biofuel has extended research works and discussions as an alternative for renewable energy sources [2]. During this process, the triglycerides in the oil will be exposed to a continuous flow of hydrogen gas at high temperature to undergo a gradual decomposition into fuel compound. One of the advantages obtained in using this method is the production of high-quality hydrocarbonbased fuel instead of fatty acid methyl esters (FAME) found in biodiesel [3]. According to previous study, fuel that contains less to no oxygen atom such as hydrocarbon, will have a shorter ignition delay and therefore exhibits better as well as low-pollutant combustion [4]. This type of fuel has similar compounds to those found in petroleum fuel, having high energy density, low viscosity, and high stability $[5,6]$.

Waste coconut oil was chosen as the hydrotreatment feed in this study with the consideration of its high availability, environmental conservation, and its usage does not cause any competition with the food industry. Waste coconut oil, which is included as one of the most frequently used cooking oil with over $3.5 \mathrm{MT} / \mathrm{annum}$ consumption $(2.5 \%$ of world vegetable production), can be considered as a promising alternative for renewable energy sources [7]. Coconut oil is an important edible oil for the food industry containing 9095\% saturated fatty acid, comprised dominantly by Lauric acid (47\%) [8]. As it was reported to give more benefits to heart health [9], coconut oil has been widely used by society as cooking oil along with palm oil [10]. The increased use of coconut oil has caused the accumulation of its waste in the environment. This type of waste was reported to contain toxic and carcinogenic compounds that may kill and contaminate many living organisms, especially in marine, and return to humans through the food chain [11]. Converting used coconut oil into biofuel is like killing two birds with one stone, not only is it going to solve an environmental problem, it is also going to offer an alternative for the new source of energy that has high availability and a low cost.

Previously, two types of materials that were found as excellent hydrotreating catalysts were supported noble metals (such as: Pd and Pt) $[8,15]$ and sulfided bimetallic catalysts (Mo- or W- based sulfides promoted with $\mathrm{Ni}$ or $\mathrm{Co}$ ) $[2,16]$. However, despite the high conversion, a few drawbacks were later discovered from the use of these two materials, including the limited availability of noble metals which leads to its exorbitant cost and the gradual desulfurization from the use of sulfided bimetallic catalyst [16]. The search of new nonnoble metal and non-sulfided catalysts is necessary.

In previous research, a bifunctional mesoporous silica catalyst containing amine functional group from 3-aminopropyltrimethoxysilane (APTMS) and $\mathrm{Ni}$ was demonstrated as a good catalyst in the hydrogenation of Free Fatty Acids (FFA) into hydrocarbon fuels with over $66 \mathrm{wt} \%$ conversion [6]. Amine group, that is actively interacting with (FFA), increases the sequestration of substrates by the catalyst and thus increasing its conversion process simultaneously. Furthermore, transition metal Ni that provides acid sites in its vacant $p$ orbital will facilitate the process of hydrotreatment in a shorter period of time [17]. However, we see a possibility of improvement by adding Mo to promote the catalytic activity of $\mathrm{Ni}$ metal. Arranging $\mathrm{Ni}$ and $\mathrm{Mo}$ in a bimetallic system was found to enhance the metal dispersion in the catalyst thus leading to better stability [18]. The selectivity of $\mathrm{Ni}$ metal in the hydrodeoxygenation of octanoic acid was found to improve with the addition of Mo according to previous research [19]. It was formerly reported that the hydrocracking of crude palm oil in the presence of NiMo-ZSM-5/MCM-41 exhibited good performance with over 63.40 wt\% conversion, which is higher in comparison to the conversion by Ni-ZSM-5/MCM-41 (53.34 wt\%) [20]. Moreover, Mo which presents as metal oxide provides surface oxygen vacancy which contributes to capturing oxygencontaining compounds, such as: FFA [3,11,15]. Based on this findings, we predicted an enhancement of FFA sequestration and product selectivity exhibited by bimetallic $\mathrm{Ni}$ Mo supported on amine-functionalized mesoporous silica ( $\mathrm{NiMo} / \mathrm{NH}_{2}-\mathrm{MS}$ ).

In this study, monometallic $\mathrm{Ni}$ and bimetallic Ni-Mo supported on aminefunctionalized mesoporous silica were synthesized as new potential catalysts for hydrotreating waste coconut oil, which breaks down into high level of FFAs at the early step of hydrogenation reactions according to the previous study [2]. Each catalyst prepared was characterized and evaluated to further discuss its plausible future application in producing fine quality fuel compounds. 


\section{Materials and Methods}

\subsection{Materials}

Silica with purity over $98.6 \%$ was extracted from Lapindo mud that was collected from Sidoarjo Regency, East Java, Indonesia [24,25]. The use of natural resources gives the benefits of its high availability and its low price. Sodium hydroxide $(\mathrm{NaOH}, \geq 97 \%)$, hydrochloric acid $(\mathrm{HCl}, 37 \%)$, cetyltrimethylammonium bromide (CTAB, $\geq 98 \%)$, nickel nitrate hexahydrate $\left(\mathrm{Ni}\left(\mathrm{NO}_{3}\right)_{2} \cdot 6 \mathrm{H}_{2} \mathrm{O}, 99 \%\right)$, ammonium he ptamolybdate tetrahydrate $\left(\left(\mathrm{NH}_{4}\right)_{6} \mathrm{Mo}_{7} \mathrm{O}_{24} \cdot 4 \mathrm{H}_{2} \mathrm{O}\right.$, 99.3\%), methanol (99.9\%), and toluene $(99.9 \%)$ were each purchased from Merck \& Co. 3-aminopropyl trimethoxysilane (APTMS, 97\%) was purchased from Tokyo Chemical Industry Co.

\subsection{Synthesis of Mesoporous Silica}

Mesoporous silica was prepared using a cetyltrimethylammonium bromide (CTAB) surfactant as a template. Powdered $\mathrm{SiO}_{2}$ was dissolved in a solution of $2 \mathrm{M} \mathrm{NaOH}$ to obtain soluble sodium silicate. Dropwise of sodium silicate was added into a CTAB solution under constant stirring at room temperature with a mole ratio of $\mathrm{SiO}_{2}$ :CTAB (1:0.5) [26]. The mixture was stood for $2 \mathrm{~h}$ before it was added with $2 \mathrm{M} \mathrm{HCl}$ to give $\mathrm{pH} 10$. The formed gel solution was moved into the autoclave and hydrothermally treated at $100^{\circ} \mathrm{C}$ for $24 \mathrm{~h}$. The final product was filtered, washed with demineralized water, and dried at $80{ }^{\circ} \mathrm{C}$ overnight. It was then calcined at $550{ }^{\circ} \mathrm{C}$ for 6 $\mathrm{h}$ with a heating rate of $5^{\circ} \mathrm{C} \cdot \mathrm{min}^{-1}$ in order to remove the CTAB surfactant.

\subsection{Impregnation of Metals into Mesoporous Silica (MS).}

The impregnation was done through a simple wet impregnation at which three sets of variations were employed including: (1) $2 \mathrm{wt} \%$ of Ni/MS, and (2) $1 \mathrm{wt} \%$ of $\mathrm{Ni}$ and $1 \mathrm{wt} \%$ of Mo/MS. Monometallic $2 \mathrm{wt} \%$ of Ni/MS was synthesized by dispersing $1.0 \mathrm{~g}$ of mesoporous silica (MS) under constant stirring at $300 \mathrm{rpm}$ in an aqueous solution containing $0.10 \mathrm{~g}$ of $\mathrm{Ni}\left(\mathrm{NO}_{3}\right)_{2} \cdot 6 \mathrm{H}_{2} \mathrm{O}$. On the other hand, the bimetallic catalyst of $1 \mathrm{wt} \%$ of $\mathrm{Ni}$ and $1 \mathrm{wt} \%$ of $\mathrm{Mo} / \mathrm{MS}$ was synthesized using co-impregnation method, where $1.0 \mathrm{~g}$ of mesoporous silica was dispersed under constant stirring at $300 \mathrm{rpm}$ in an aqueous solution containing $0.05 \mathrm{~g}$ of $\mathrm{Ni}\left(\mathrm{NO}_{3}\right)_{2} \cdot 6 \mathrm{H}_{2} \mathrm{O}$ and $0.02 \mathrm{~g}$ of $\left(\mathrm{NH}_{4}\right)_{6} \mathrm{Mo}_{7} \mathrm{O}_{24} \cdot 4 \mathrm{H}_{2} \mathrm{O}$ [27]. Each of these solutions were evaporated at $80{ }^{\circ} \mathrm{C}$ [28]. The prepared catalysts were dried overnight at 100 ${ }^{\circ} \mathrm{C}$. Each was then calcined at $500{ }^{\circ} \mathrm{C}$ with a heating rate of $5{ }^{\circ} \mathrm{C} \cdot \mathrm{min}^{-1}$ under the flow of $\mathrm{N}_{2}$ $\left(20 \mathrm{~mL} \cdot \mathrm{min}^{-1}\right)$ for $3 \mathrm{~h}$, followed by reduction at $450{ }^{\circ} \mathrm{C}$ in a constant flow of $\mathrm{H}_{2}\left(20 \mathrm{~mL} \cdot \mathrm{min}^{-1}\right)$ for $5 \mathrm{~h}$. The metal loaded in the pore of MS was determined quantitatively by using Atomic Absorption Spectrometer (AAS).

\subsection{Synthesis of Amine Functionalized Metal/} MS.

Amine functionalized mesoporous catalysts were prepared by grafting 3 -APTMS $(1 \mathrm{mmol}$, $0.18 \mathrm{~g}, 174 \mu \mathrm{L})$ to the surface of each metalsupported mesoporous silica catalyst $(0.5 \mathrm{~g})$ in $20 \mathrm{~mL}$ of refluxed toluene under constant stirring for $6 \mathrm{~h}$ at $90^{\circ} \mathrm{C}$. The grafted mesoporous silica was collected by centrifugation at 2000 rpm for 20 minutes, then washed several times by using methanol to remove the excess APTMS molecules. The final product was dried at $80^{\circ} \mathrm{C}$.

\subsection{Characterization and Activity Test}

The surface area and pore size of each mesoporous catalysts prepared were analyzed by using surface area analyzer Nitrogen gas sorption Quantachrome NOVAtouch 4LX. The surface areas were calculated using Brunauer Emmett - Teller (BET) method and the pore size distribution was calculated using Barrett Joyner - Halenda (BJH) method. The functional group of mesoporous silica was identified by using FTIR Shimadzu Prestige-21, analyzed in the range of 400-4000 $\mathrm{cm}^{-1}$ using $\alpha \mathrm{KBr}$ disc technique. The surface image of catalyst was captured by using Scanning Electron Microscopy (SEM) JSM-6510LA operated at $15 \mathrm{kV}$ accelerating voltage. The crystal structure of each catalyst was characterized at wide angle by using X-Ray Diffraction Philips X'Pert MPD using $\mathrm{Cu}$ target at $40 \mathrm{kV}$ and $30 \mathrm{~mA}$. Atomic Absorption Spectroscopy (AAS) Perkin Elmer $5100 \mathrm{PC}$ was used to determine the quantity of the metal impregnated into the mesoporous support. The pore image was examined by using Transmission Electron Microscopy (TEM) JEOL-JEM-1400 with an electron beam of 120 $\mathrm{kV}$. The sequestration of feed was observed by collecting catalyst material 30 minutes after the hydrotreating occurred and analyzing it using FTIR Shimadzu Prestige-21 for identifying any vibration from the feed molecules. Liquid products obtained from catalytic activity tests were identified and analyzed by using GC-MS QP2010S Shimadzu. 
The catalytic activity was tested towards the hydrotreatment process of used coconut oil. The test was done in accordance with the published procedure [29]. The feed used in the test was coconut oil that had been used twice as frying oil. The ratio of catalyst and feed put during the test was $1 / 50(\mathrm{w} / \mathrm{w})$. For instance, in this study, $0.1 \mathrm{~g}$ of catalyst was used in the hydrotreatment of $5 \mathrm{~g}$ of used oil. The hydrotreatment process was done in a semi-batch reactor as illustrated in Figure 1. The reaction was carried out at $450{ }^{\circ} \mathrm{C}$ for $2 \mathrm{~h}$. The product generated would pass through a condenser where it was cooled down to room temperature and collected by a containing flask. The final product was then weighed and analysed by using GC-MS. The product conversion was determined gravimetrically by using calculation as written in equations below:

$$
\begin{aligned}
& T(w t \%)=\frac{w_{f}-w_{r}}{w_{f}} \times 100 \% \\
& L(w t \%)=\frac{w_{l}}{w_{f}-w_{r}} \times 100 \% \\
& C(w t \%)=\frac{w_{C f i n}-w_{C i n}}{w_{f}-w_{r}} \times 100 \% \\
& G(w t \%)=T(w t \%)-L(w t \%)-C(w t \%) \\
& \text { Selectivity }(w t \%)=\frac{A_{c}}{A_{T}} \times L(w t \%)
\end{aligned}
$$

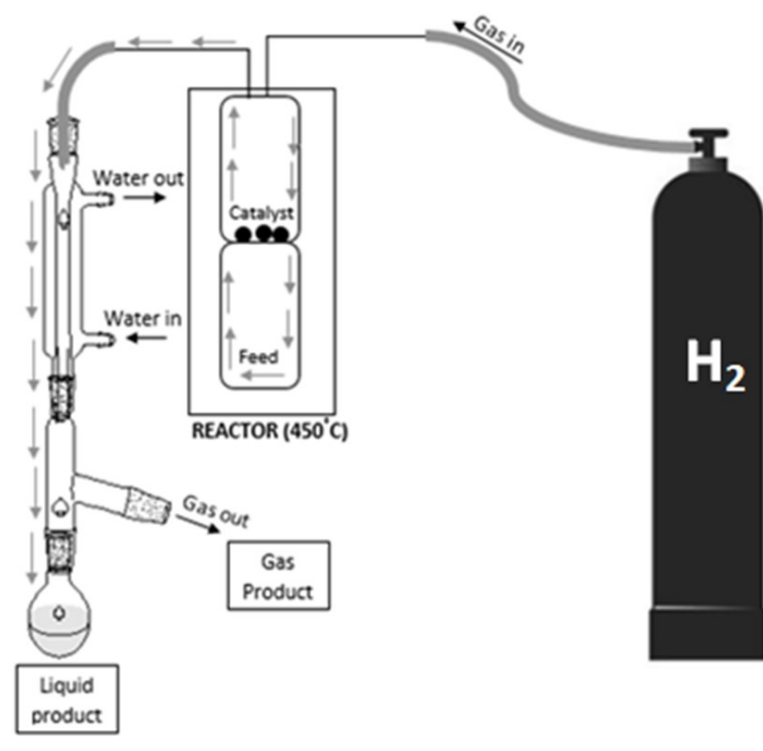

Figure 1. Semi-batch reactor used in the hydrotreatment of used coconut oil.
Where $T$ is total conversion (wt\%), $L$ is liquid conversion (wt\%), $C$ is coke formation (wt\%), $G$ is gas conversion ( $\mathrm{wt} \%), w_{\mathrm{f}}$ is initial weight of feed $(\mathrm{g}), w_{\mathrm{r}}$ is residue weight after hydrotreatment $(\mathrm{g}), w_{1}$ is weight of liquid product obtained $(\mathrm{g}), w_{\text {cfin }}$ is weight of catalyst after hydrotreatment $(\mathrm{g}), w_{\text {cin }}$ is initial weight of catalyst (g), $A_{\mathrm{c}}$ is GC-MS area of compound, $A_{\mathrm{T}}$ is the total GC-MS area.

\section{Results and Discussion}

\subsection{Catalyst Characterization}

The synthesis of the mesoporous silica support in this work was done by employing hydrothermal conditions to CTAB-arranged silica as referred to a previously published method [26]. The removal of CTAB surfactant as the templating agent was confirmed through an FTIR analysis which examined both the uncalcined and the calcined mesoporous silica (Figure 2). Vibration bands at wavenumber 1087, 1226, and $956 \mathrm{~cm}^{-1}$ were shown to appear indicating the presence of - $\mathrm{Si}-\mathrm{O}-\mathrm{Si}-$ bond and $-\mathrm{Si}-\mathrm{OH}$. These are all the essential bondings found in the structure of mesoporous silica. The broad band showed at wavenumber 3433 $\mathrm{cm}^{-1}$ appeared from the stretching vibration of $-\mathrm{OH}$ bond in $\mathrm{Si}-\mathrm{OH}$ [30]. It can be seen that there are some changes in the FTIR spectra after the calcination process with the disappearance of bands at wavenumber 2924, 2854, and $1473 \mathrm{~cm}^{-1}$. These are the antisymmetric and symmetric stretching bands of $-\mathrm{CH}_{3}$ as well as the stretching band of $\mathrm{RN}\left(\mathrm{CH}--_{-3}\right)_{3}{ }^{+}$, respectively, from the surfactant molecule [31]. With its disappearance after calcination, the removal of the surfactant molecule is confirmed.

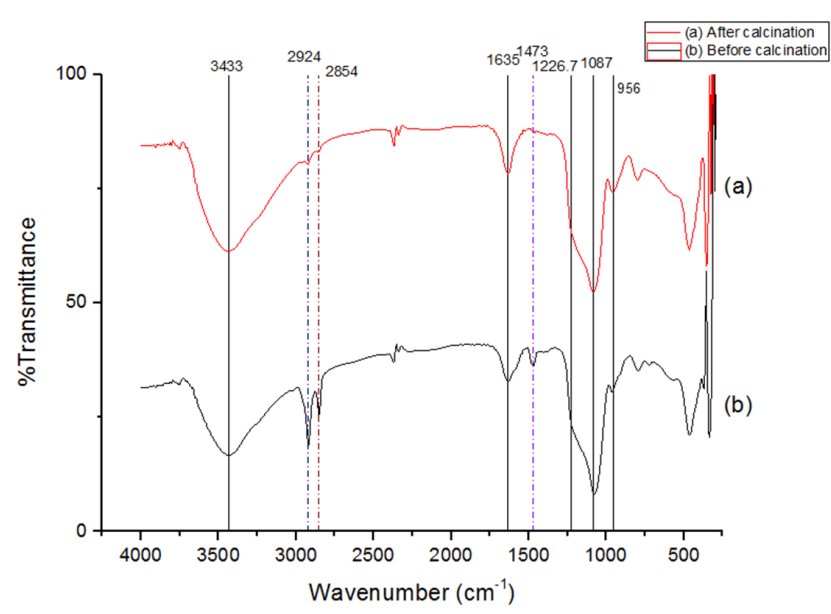

Figure 2. FTIR spectra of mesoporous silica. 

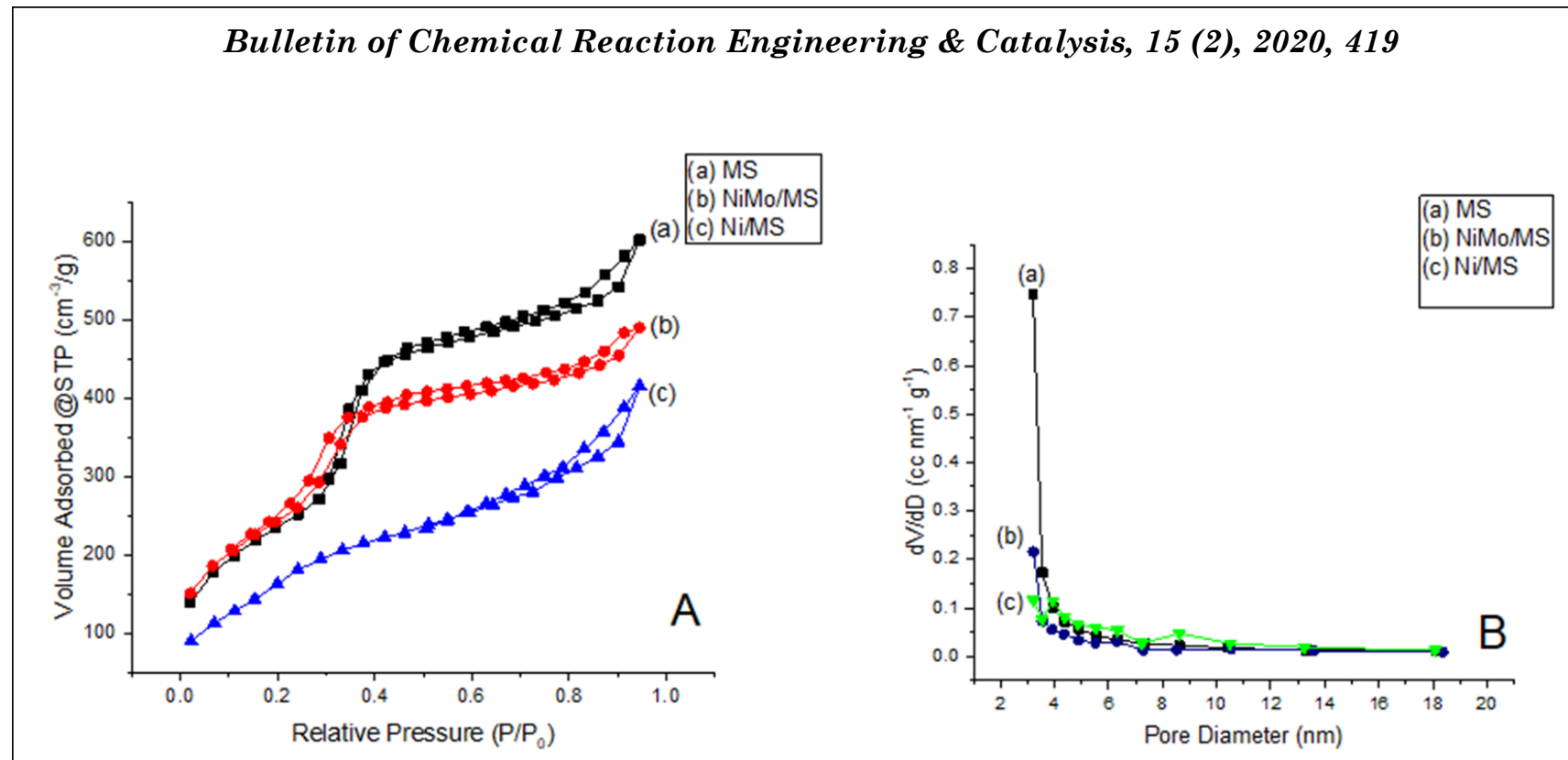

Figure 3. (a) Nitrogen sorption isotherm graph, (b) Pore size distribution graph.


Figure 4. TEM images of (a) MS, (b) Ni/MS, (c) NiMo/MS, (d) NiMo / $\mathrm{NH}_{2}-\mathrm{MS}$. 

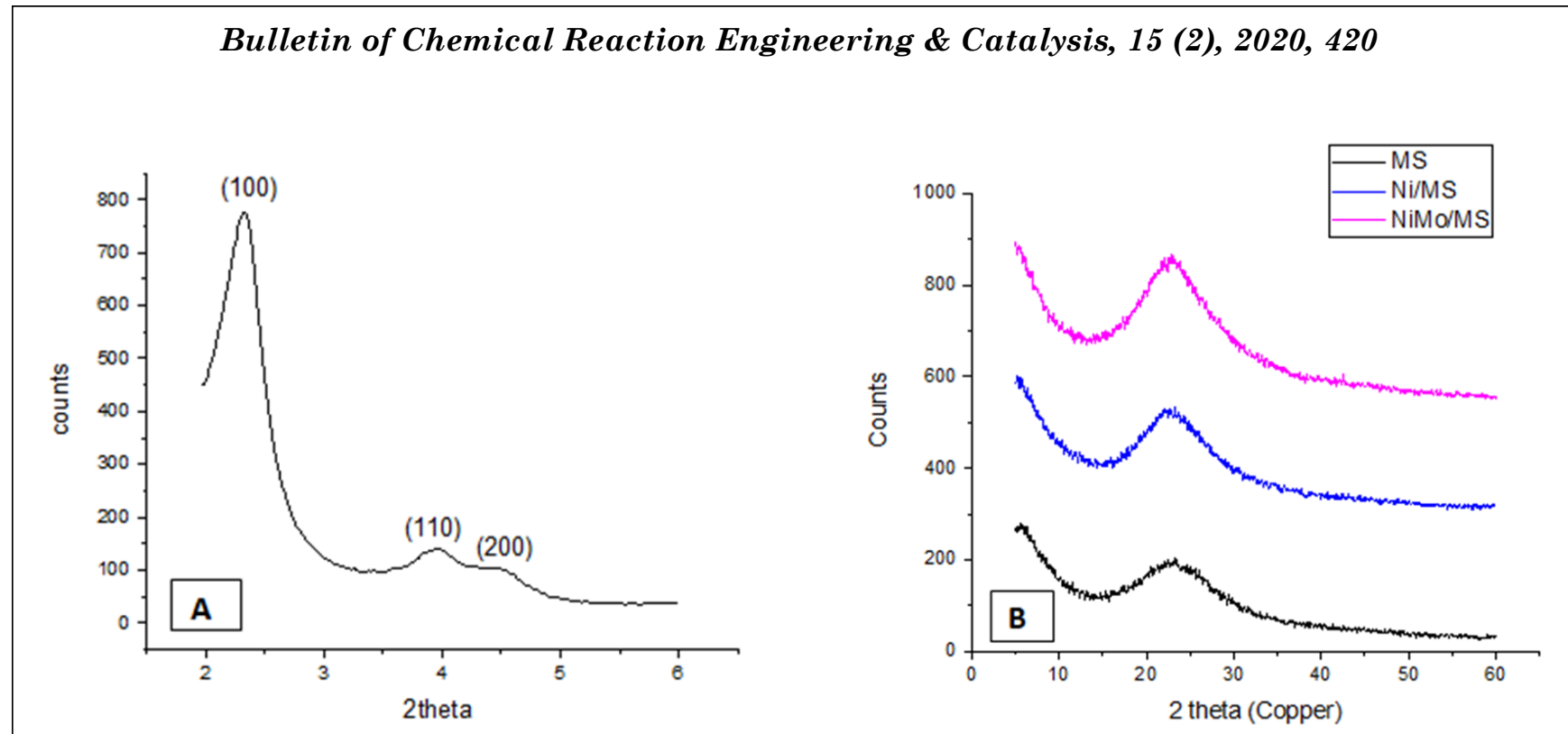

Figure 5. a) Low-angle XRD diffractogram of mesoporous silica (MS); b) Wide-angle XRD of metal loaded mesoporous silica.



(a)

(b)

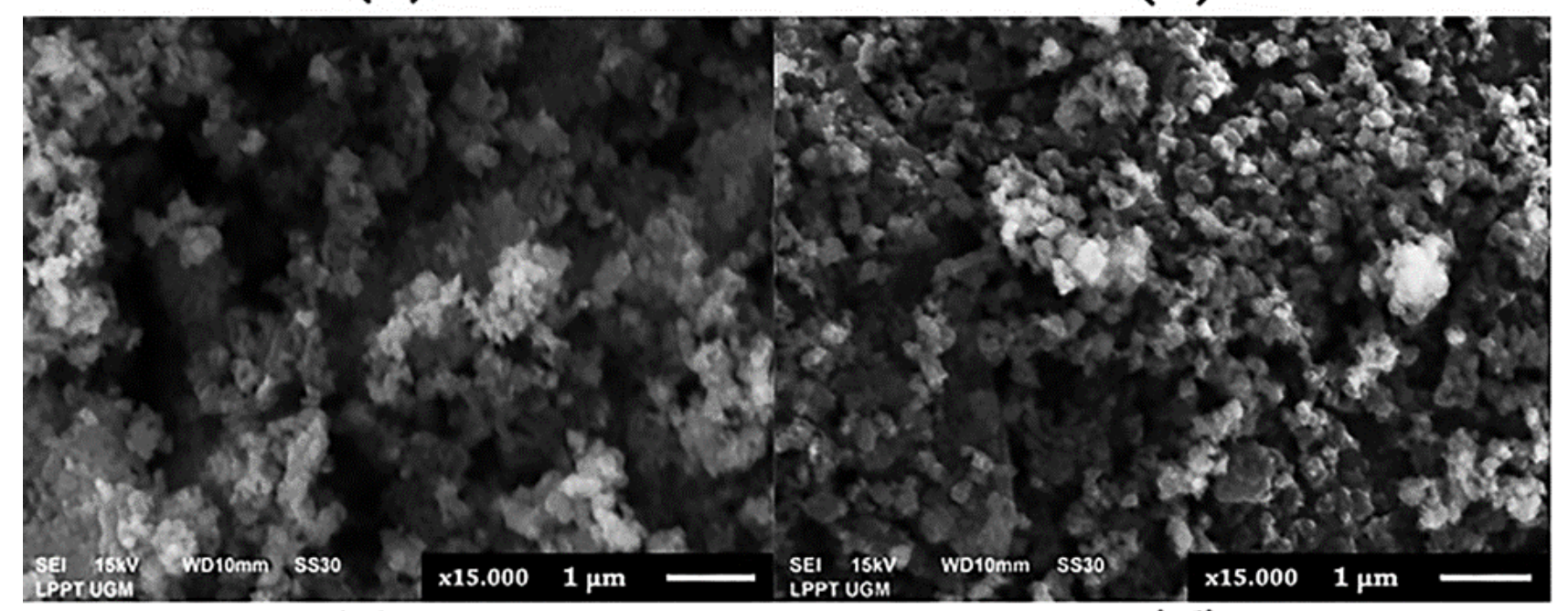

(c)

(d)

Figure 6. SEM images of (a) MS, (b) Ni/MS, (c) Mo/MS, (d) NiMo/MS. 
The mesoporous behavior of the prepared silica support was confirmed through nitrogen gas adsorption desorption analysis. This was confirmed by the 'Type IV' isotherm model graph exhibited by the material in the gas adsorption analysis (Figure $3 \mathrm{a}$ ). It is seen that the material exhibited 'Type IV' isotherm graph, which is classified as mesoporous material according to IUPAC classification. The mesoporous support was revealed to have a large BET surface area, total pore volume, and average pore diameter $877 \mathrm{~m}^{2} \cdot \mathrm{g}^{-1}, 0.93 \mathrm{~cm}^{3} \cdot \mathrm{g}^{-1}$, and $4.32 \mathrm{~nm}$, respectively. The pore size distribution revealed a pore diameter within the range of 3.2 to $18 \mathrm{~nm}$, which falls in mesopore region. The isotherm model is retained after monometallic and bimetallic impregnation, indicating the preservation of mesoporous behaviour. There was, however, a change in hysteresis loop with the metal modification. Initially, it is seen that the synthesized mesoporous silica generated H1 hysteresis loop which corresponds to material with well-defined cylindrical pore channels [32]. While bimetallic NiMo addition was seen to maintain this pore structure by continuing to display H1 hysteresis loop, interestingly, monometallic $\mathrm{Ni}$ addition caused a shift in hysteresis loop into H2 (b). According to IUPAC classification, this type of hysteresis loop is associated to the occurrence of pore-blocking that may take place after the deposition of monometallic $\mathrm{Ni}$ metal [33]. With the occurrence of pore blocking, it is obvious that the surface area provided by Ni/MS (670.48 $\left.\mathrm{m}^{2} \cdot \mathrm{g}^{-1}\right)$ will be lower than the unmodified MS $\left(877.39 \mathrm{~m}^{2} \cdot \mathrm{g}^{-1}\right)$.

On the other hand, the presence of Mo added via co-impregnation method is shown to improve the pore blocking caused by Ni particles in NiMo/MS, which was implied by the decrease of surface area drop $\left(873.89 \mathrm{~m}^{2} \cdot \mathrm{g}^{-1}\right)$ and the preservation of $\mathrm{H} 1$ hysteresis loop (Figure $3 a)$. This is possibly due to the enhancement of metal dispersion in bimetallic system, which leads to the generation of smaller metal particles. The interaction between the two metals created a competition during and thus improves the dispersion of metals throughout the pore of silica. This, in turn, prevents the growth of each metal particle, which limits pore blockage. The amount of metal successfully impregnated was determined quantitatively using AAS instrument as shown in Table 1.

In order to observe the occurrence of pore blocking, each catalyst pores were captured using TEM imaging (Figure 4). In the figure, the bright region appeared represents the pore of the support, while the grey region positioned next to it acts as the wall of the parent material. The metal was represented by the dark particles dispersed along the pore of the support as presented in Figure $4 \mathrm{~b}-\mathrm{d}$. The nature of metal dispersion differed for each catalyst prepared. As expected, the pore in monometallic Ni/MS catalyst is seen to be covered by the accumulated metal particles (dark), indicating the occurrence of pore blocking (Figure $4 \mathrm{~b}$ ). In contrast, the growth of metal particles is seen to be less severe in the pore of bimetallic NiMo/MS as the pore is seen to be less occupied compared to Ni/MS. This confirms the presence of smaller metal particle in bimetallic catalyst.

Through a low-angle XRD analysis shown in Figure 5a, it is seen that the silica support (MS) exhibits sharp (100) diffraction peak at $2 \theta$ $2.33^{\circ}$ and two additional peaks indexed as (110) and (200) at $2 \theta 3.94^{\circ}$ and $4.49^{\circ}$.

Table 1. Catalyst properties.

\begin{tabular}{|c|c|c|c|c|c|c|c|}
\hline \multirow[t]{2}{*}{ Catalyst } & \multirow{2}{*}{$\begin{array}{l}\text { Surface } \\
\text { Area } \\
\left(\mathrm{m}^{2} \cdot \mathrm{g}^{-1}\right)\end{array}$} & \multirow{2}{*}{$\begin{array}{l}\text { Total Acid } \\
\text { Amount } \\
\text { (mmol.g }{ }^{-1} \text { ) }\end{array}$} & \multirow{2}{*}{$\begin{array}{c}\text { Pore } \\
\text { volume } \\
\left(\mathrm{cm}^{3} \cdot \mathrm{g}^{-1}\right)\end{array}$} & \multirow{2}{*}{$\begin{array}{l}\text { Total Pore } \\
\text { Volume } \\
\left(\mathrm{cm}^{3} \cdot \mathrm{g}^{-1}\right)\end{array}$} & \multirow{2}{*}{$\begin{array}{l}\text { Average pore } \\
\text { diametera } \\
(\mathrm{nm})\end{array}$} & \multicolumn{2}{|c|}{$\begin{array}{c}\text { Metal loading } \\
(\mathrm{wt} \%)^{\mathrm{c}}\end{array}$} \\
\hline & & & & & & $\mathrm{Ni}$ & Mo \\
\hline $\mathrm{MS}$ & 877.39 & 4.61 & 0.34 & 0.93 & 4.32 & - & - \\
\hline $\mathrm{Ni} / \mathrm{MS}$ & 670.48 & 8.68 & 0.29 & 0.64 & 4.08 & 2.02 & - \\
\hline NiMo/MS & 873.89 & 6.17 & 0.18 & 0.76 & 3.32 & 0.92 & 1.03 \\
\hline $\mathrm{NH}_{2} / \mathrm{MS}$ & 311.79 & 2.04 & 0.08 & 0.25 & 3.20 & - & - \\
\hline $\mathrm{Ni} / \mathrm{NH}_{2}-\mathrm{MS}$ & 328.68 & 5.44 & 0.08 & 0.25 & 3.10 & 1.90 & - \\
\hline $\mathrm{NiMo} / \mathrm{NH}_{2}-\mathrm{MS}$ & 325.13 & 4.46 & 0.14 & 0.30 & 3.22 & 0.83 & 1.08 \\
\hline
\end{tabular}

aSurface area, pore volume, total pore volume, and diameters were determined by using BET and BJH theory, ${ }^{\mathrm{b}}$ Total acid amount was determined using gravimetrically using $\mathrm{NH}_{3}$ gas as a basic adsorbate, ${ }^{\mathrm{c}}$ Metal loading was determined by using atomic absorption spectrophotometer (AAS). 
According to the previous research, the appearance of strong peak (100) and the two weak peaks of (110) and (200) indicates a hexagonal mesostructure material with a high degree of structure ordering [34]. The prepared catalysts were examined using wide-angle XRD (Figure 5b). It can be seen that all materials exhibited similar reflection at $2 \theta 23^{\circ}$, indicating the amorphous structure of silica support (JCPDS card no. 01-086-1561). An addition of metal peaks was not found in the diffractogram after impregnation process, suggesting that it exists as small-sized particles in an amorphous phase. The metal was captured by SEM images (Figure 6) as bright-colored particles fairly distributed on the surface of mesoporous silica, indicating an element with high atomic numbers which

(a) Mesoporous APTMS

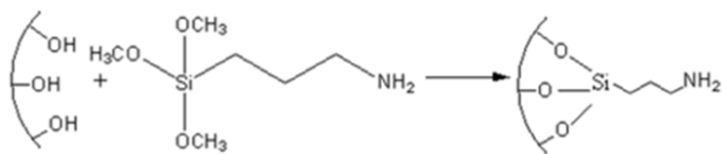
$\mathrm{NH}_{2}$ Mesoporous

(b)



Figure 7. (a) Functionalization of amine; (b) FTIR spectra of; (a) Ni/MS, (b) $\mathrm{Ni} / \mathrm{NH}_{2}-\mathrm{MS}$, (c) $\mathrm{NiMo} / \mathrm{MS}$, (d) NiMo/NH $\mathrm{N}_{2}-\mathrm{MS}$. therefore generates higher intensity due to the increasing number of backscattered electron $[35,36]$. The presence of each metal was detected through elemental analysis of EDX as shown in Figure 10. From the surface image generated by SEM, it is seen that the catalyst material possessed a wormhole-like morphology.

The functionalization of amine group is described in Figure 7. The addition of the amine group leads to a further decrease of catalyst surface area and pore volume as shown in Table 1. This is because 3aminopropyl functional group has a longer chain compared to the initial silanol group, hence will occupy more space in the pore and decrease its volume capacity. The addition of 3aminopropyl group was identified through FTIR. As shown in Figure 7b, the FTIR spectra reveals the appearance of bands at wavenumber $1558 \mathrm{~cm}^{-1}$ and $3400 \mathrm{~cm}^{-1}$ after the grafting process which indicates the bending and stretching of $-\mathrm{NH}_{2}$ bond. Antisymmetrical stretching band of $-\left(\mathrm{CH}_{2}\right)$ - at $2931 \mathrm{~cm}^{-1}$ was also shown in the $\mathrm{Ni} / \mathrm{NH}_{2}-\mathrm{MS}$ and $\mathrm{NiMo} / \mathrm{NH}_{2}$ MS catalysts. The band of $\mathrm{Si}-\mathrm{OH}$ vibration at $956 \mathrm{~cm}^{-1}$ weakens after amine addition, which further confirms the replacement of $\mathrm{Si}-\mathrm{OH}$ with $\mathrm{Si}-\mathrm{O}-\mathrm{Si}$ as described by grafting reaction illustrated in Figure 7a. As depicted by the TEM image in Figure 4d, the pore was shown to darken after amine addition. This is because the pore is being filled and occupied by molecules of 3-aminopropyl group which hindered the transmission of electron to fluorescent screen in TEM instrument, thus producing a darker image.

\subsection{Catalytic Activity}

The catalytic activity of each material prepared was evaluated. The hydrotreatment of used coconut oil was carried out at $450{ }^{\circ} \mathrm{C}$ under the flow of $\mathrm{H}_{2}$ gas for 2 hours. According

Table 2. Total conversion and product distribution from the hydrotreatment of waste coconut oil over different catalysts.

\begin{tabular}{|c|c|c|c|c|c|c|c|}
\hline \multirow{3}{*}{ Materials } & \multirow{3}{*}{$\begin{array}{l}\text { Conversion } \\
\text { (wt\%) }\end{array}$} & \multicolumn{6}{|c|}{ Product distribution (wt\%) } \\
\hline & & \multirow{2}{*}{ Gas } & \multicolumn{4}{|c|}{ Liquid } & \multirow{2}{*}{ Coke } \\
\hline & & & Hydrocarbon & FFA & Organics & Total & \\
\hline Thermal & 99.6 & 19.2 & 51.0 & 26.0 & 3.4 & 80.4 & 0.0 \\
\hline $\mathrm{Ni} / \mathrm{MS}$ & 99.7 & 26.8 & 47.7 & 19.4 & 5.4 & 72.8 & 0.1 \\
\hline NiMo/MS & 99.7 & 17.3 & 58.1 & 22.4 & 1.9 & 82.4 & 0.03 \\
\hline $\mathrm{NH}_{2}-\mathrm{MS}$ & 99.6 & 21.5 & 55.9 & 15.4 & 6.2 & 77.5 & 0.6 \\
\hline $\mathrm{Ni} / \mathrm{NH}_{2}-\mathrm{MS}$ & 99.9 & 21.7 & 68.8 & 7.3 & 1.8 & 77.9 & 0.2 \\
\hline $\mathrm{NiMo} / \mathrm{NH}_{2}-\mathrm{MS}$ & 99.4 & 22.7 & 65.6 & 8.9 & 1.8 & 76.3 & 0.4 \\
\hline
\end{tabular}


to a reaction mechanism proposed in a former study, used oil undergoes gradual reduction to FFA, aldehydes / ketones, alcohols, and hydrocarbon compounds, respectively, in the hydrotreatment at $450{ }^{\circ} \mathrm{C}$ [37]. This mechanism is seen to be compatible to the one occurred in this study due to the amount of FFA, aldehydes, ketones and alcohol compounds found in all liquid products (Table 3). As the reaction involves the removal of oxygenated functional group, the mechanism is referred as deoxygenation, which may include three possible pathways: decarbonylation, decarboxylation or hydrodeoxygenation [38,39]. The catalyst effectiveness in carrying out deoxygenation reaction can be observed by assessing the number of oxygenated compounds found in the collected liquid product. Catalyst with good deoxygenation activity should be able to generate low level of oxygenated compounds during the course of hydrotreatment.

Prior to evaluating all catalyst materials, a thermal hydrotreatment was first conducted by simply exposing feed molecules to the flow of $\mathrm{H}_{2}$ gas at $450{ }^{\circ} \mathrm{C}$, without the presence of catalyst. From this implementation, the result showed high level of liquid product (80.4 wt\%) containing $51.1 \mathrm{wt} \%$ hydrocarbon and $29.4 \mathrm{wt} \%$ oxygenated compounds. Despite the high liquid conversion, this was, in fact, the highest oxygenated compound obtained from all course of hydrotreatment done in this study. The result indicates that the occurrence of deoxygenation pathway did not effectively occur in this method. It is very likely that this is because thermal hydrotreatment predominantly follows the free radical mechanism, where it is solely caused the cracking or the splitting of molecules into lighter fractions, which does not necessarily focus on the removal of oxygenated functional group [40]. With the amount of FFA impurities the product contains, it is deemed to be unfavourable for fuel. Therefore, the use of catalysts is expected to improve the deoxygenation performance and, thus, the selectivity towards the generation of liquid hydrocarbon products. Overall, it is seen that all catalytic hydrotreatment was able to reduce the composition of oxygenated compound in the collected liquid product. This subsequently inferred the improvement of deoxygenation mechanism from the thermal hydrotreatment.

Firstly, we compared the performance of catalyst with and without amine group in the hydrotreatment of waste coconut oil. Interestingly, the employment of amine group showed different effects in a monometallic $\mathrm{Ni}$ based catalyst and in a bimetallic NiMo based catalyst. According to the result, amine group addition has shown to increase the generation of liquid product for Ni/MS catalyst from 72.8 wt\% to $77.9 \mathrm{wt} \%$ (Ni/ $\left.\mathrm{NH}_{2}-\mathrm{MS}\right)$, as opposed to the decrease of liquid product for bimetallic NiMo/MS from $82.4 \mathrm{wt} \%$ to $76.3 \mathrm{wt} \%$ (NiMo/NH $2-\mathrm{MS})$. However, we found a drastic decrease of oxygenated compound in the liquid product generated by both amine functionalized catalysts $\left(\mathrm{Ni} / \mathrm{NH}_{2}-\mathrm{MS}\right.$ and $\mathrm{NiMo} / \mathrm{NH}_{2}-\mathrm{MS}$ ), which indicates the improvement of deoxygenation activity with the modification.

In order to seek more understanding towards the presented data, the differences between monometallic Ni/MS and bimetallic Ni$\mathrm{Mo} / \mathrm{MS}$ catalysts are assessed. The hydrotreatment performed in the presence of $\mathrm{Ni} / \mathrm{MS}$ was found to generate the highest gas product in this study, with over $26.8 \mathrm{wt} \%$. This is possibly due to Ni tendency to conduct catalytic cracking over other mechanism on the acid sites it provides [41]. This is proven by the total acid value shown in Table 1 , where it is seen that Ni/MS (8.68 mmol.g-1) exhibited the highest value among the other catalysts prepared. In the process of catalytic cracking, it is probable that molecules are continuously converted into lighter fractions, which may eventually release as gas compounds. This leads to the low liquid conversion Ni/MS produced, as opposed to its high gas yield.

In contrast, the addition of Mo in NiMo/MS catalyst resulted $9.6 \mathrm{wt} \%$ increment of liquid product from $72.8 \mathrm{wt} \%$ to $82.4 \mathrm{wt} \%$. The data suggests that the metal modification had managed to limit the cracking activity of $\mathrm{Ni}$ and lessen the production of gas molecules in return. The decrease of cracking activity may be due to the interaction between the combined $\mathrm{Ni}$ and Mo metals, which decrease the effectiveness of $\mathrm{Ni}$ acid site where the cracking mechanism is facilitated. This is proven by the decrease of acid value found in NiMo/MS (6.17 mmol.g-1). The positive effect of Mo addition also lies in the increase of $\mathrm{Ni}$ dispersion which subsequently leads to the decrease of coke formation to $0.03 \mathrm{wt} \%$ (Table 2). A higher metal dispersion would consequently lead to the formation of smaller metal size on the surface of support [17], which would play a key role in reducing carbon deposition [42,43]. This is a very important consideration as carbon deposition can lead to the catalyst deactivation and deliberately halt the occurrence of conversion process. In addition, with the presence of smaller 
$\mathrm{Ni}$ particles due to the high metal dispersion, the active surface area of the metal in the catalyst, which facilitates the occurrence of hydrogenation reaction, will be higher in value. Therefore, it would improve the catalytic activity of the catalyst. Despite the positive effect, however, it is seen that the deoxygenation activity had not been much improved with bimetallic condition, as the generation of oxygenates remained significantly the same $(24.3 \mathrm{wt} \%)$. The high amount of FFA (22.4 wt\%) released from the catalytic hydrotreatment indicates that the successive reduction of oxygenated functional group did not occur to completeness in this process. The lack of hydrogen adsorption site in the catalyst material may be one of the reasons of the incomplete reduction process, which was caused by the less amount of $\mathrm{Ni}$ loading done in the bimetallic catalyst (Table 1). Hydrogen chemisorption only occurred in the d-orbital provided by Ni metals, as according to a previous study, molybdenum does not adsorb any hydrogen gas [44]. As less hydrogen is being provided by the catalyst surface, reduction of used coconut oil to form hydrocarbons does not occur properly, resulting the release of high level oxygenated compounds. Another possible reason is because the occurrence of reduction may not be controlled and localized at oxygenated functional group in this catalyst. It may occur randomly in other possible part of the molecule, i.e. to convert double bond into single bond (hydrogenation of alkene group). In order to check this assumption, the amount of alkane and alkene contained in the liquid product is calculated (Table 3). As expected, it is seen that the NiMo/MS catalyst generates the highest ratio of alkane/alkene (1.41), indicating that it produces the highest amount of alkane among the other catalyst materials. From the result, it can be inferred that the hydrogenation of double bonds is most likely to occur with the use of NiMo/MS, confirming that the catalytic reduction process may not be focused in the oxygenated functional group.

The addition of amine group to the structure of catalyst is conducted to improve the catalyst ability in sequestering feed molecules during the occurrence of hydrotreatment process. According to previous study, in the early stage of hydrotreatment, the mono-, di-, and triglycerides of waste coconut oil will break down into various FFA [2]. The basicity of amine group should be able to capture and pull the carboxylic acid group in FFA compound closer to the metal rich surface of catalyst where the conversion process occurs [6]. Therefore, not only more compounds are expected to be converted, the reaction will also be more localized and focused in the carboxylic acid part of feed, as it is closer to the surface of catalyst. With the majority of hydrogenation occurs in the oxygenated group, deoxygenation would proceed more effectively, generating liquid product with less oxygenates and higher hydrocarbons. This is confirmed by the result presented in Table 2. The drastic decrease of oxygenated compounds generated by both amine functionalized catalysts $\left(\mathrm{Ni} / \mathrm{NH}_{2}-\mathrm{MS}\right.$ and $\mathrm{NiMo} / \mathrm{NH}_{2}-\mathrm{MS}$ ) has proven the improvement of deoxygenation activity, respectively.

The increase of liquid product produced by amine functionalized monometallic Ni/MS indicates that the modification decreases $\mathrm{Ni}$ tendency to perform cracking mechanism which leads to less production of gas fractions. This may be due to the role of amine group which gradually drives the hydrogenation to occur specifically in the carboxylic acid group and thus shifts the selectivity towards deoxygenation reaction. Another explanation to this lies in the possible interaction between electronrich nitrogen in the grafted amine group with the acid site of Ni. Cracking mechanism is known to occur in the Brønsted acid site of $\mathrm{Ni}$ [41]. If the acid sites of $\mathrm{Ni}$ conducts an interaction with the neighboring amine group, its effectiveness would simultaneously decrease, thus leading to the decrease of cracking tendency. This is confirmed by the data shown in Table 1, where it is seen that $\mathrm{Ni} / \mathrm{NH}_{2}$-MS (5.44 mmol $\mathrm{g}^{-1}$ ) exhibited a lower acidity compared to $\mathrm{Ni} / \mathrm{MS}\left(8.68 \mathrm{mmol} \mathrm{g}^{-1}\right)$. It has also been stated in a previous research that the addition of amine group has caused a steric hindrance with the accumulation of organics in the pore of support, which limits the access of feed and reactants to the metal acid centers.

On the other hand, the liquid conversion generated by bimetallic NiMo/MS was shown to undergo $6.1 \mathrm{wt} \%$ drop with the employment of amine group. The decrease of liquid conversion may be linked to the increase of gas yield that are produced as a by-product of deoxygenation reaction (i.e. $\mathrm{H}_{2} \mathrm{O}, \mathrm{CO}_{2}$, and $\mathrm{CO}$ ) $[38,39]$. The improvement of deoxygenation activity with the use of catalyst is confirmed by the drastic decrease of oxygenates contained in the liquid product collected (10.7 wt\%). As oxygenated functional group is being removed, the feed molecules are converted into a lighter hydrocarbon compound, which affects the overall weight of liquid product. The increase production of hydrocarbons had shown to go from 58.7 $\mathrm{wt} \%(\mathrm{NiMo} / \mathrm{MS})$ to $65.6 \mathrm{wt} \%\left(\mathrm{NiMo} / \mathrm{NH}_{2}-\mathrm{MS}\right)$. 
Table 3. Product selectivity of hydrotreatment process over each catalyst.

\begin{tabular}{|c|c|c|c|c|c|}
\hline \multirow{2}{*}{ Compound } & \multicolumn{5}{|c|}{ Product selectivity (wt\%) } \\
\hline & Thermal & $\mathrm{Ni} / \mathrm{MS}$ & NiMo/MS & $\mathrm{Ni} / \mathrm{NH}_{2}-\mathrm{MS}$ & $\mathrm{NiMo} / \mathrm{NH}_{2}$-MS \\
\hline \multicolumn{6}{|l|}{ Hydrocarbon compound } \\
\hline Gasoline & 33.76 & 9.87 & 9.92 & 31.91 & 43.23 \\
\hline $\mathrm{C} 6$ & 1.38 & & & 0.59 & 0.44 \\
\hline $\mathrm{C} 7$ & 2.25 & & & 2.59 & 1.14 \\
\hline $\mathrm{C} 8$ & 2.40 & 0.60 & 0.41 & 2.87 & 2.94 \\
\hline C9 & 1.97 & 0.95 & 1.40 & 4.60 & 5.31 \\
\hline $\mathrm{C} 10$ & 25.77 & 3.15 & 2.36 & 5.86 & 5.44 \\
\hline C11 & & 5.17 & 5.75 & 15.31 & 27.95 \\
\hline Kerosene & 17.25 & 34.55 & 44.78 & 28.53 & 13.93 \\
\hline $\mathrm{C} 12$ & 8.91 & 28.72 & 38.08 & 10.62 & 3.71 \\
\hline $\mathrm{C} 13$ & 8.34 & 0.09 & 1.31 & 7.07 & 7.80 \\
\hline C14 & & 5.75 & 5.39 & 10.63 & 2.28 \\
\hline $\mathrm{C} 15$ & & & & 0.21 & 0.14 \\
\hline Diesel (C16 - C22) & - & 3.29 & 3.37 & 8.33 & 8.49 \\
\hline Alkane/Alkene & 1.61 & 1.09 & 1.41 & 1.12 & 0.56 \\
\hline Free Fatty Acid (FFA) & 26.00 & 19.40 & 22.40 & 7.30 & 8.90 \\
\hline Acetic acid & & & & 1.37 & 1.65 \\
\hline Hexanoic acid & & & 0.57 & 0.73 & \\
\hline Heptanoic acid & & 0.52 & & & \\
\hline Octanoic acid & & 3.38 & 6.56 & 2.38 & 3.69 \\
\hline Nonanoic acid & & 0.15 & 0.30 & 0.22 & 0.30 \\
\hline Decanoic acid & 3.84 & 4.52 & 4.52 & 2.24 & 1.99 \\
\hline Dodecanoic acid & 13.92 & 10.87 & 10.48 & 0.18 & \\
\hline Tetradecanoic acid & & & & 3.18 & \\
\hline Cyclopentaundecanoic acid & 8.19 & & & & \\
\hline Octadecanoic acid & & & & 0.08 & \\
\hline 9-Octadecenoic acid & & & & & 1.29 \\
\hline Aldehydes/Ketones & - & 0.37 & & 0.54 & 0.66 \\
\hline Dodecanal & & 0.37 & & 0.28 & 0.35 \\
\hline 2-methyl-3-decanone & & & & 0.26 & 0.31 \\
\hline Alcohols & 1.38 & 3.82 & 1.4 & 0.26 & 0.61 \\
\hline 1-Octanol & & 2.56 & & & \\
\hline \multicolumn{6}{|l|}{ 1-Dodecanol } \\
\hline 1-Tetradecanol & & 0.14 & 0.58 & 0.09 & \\
\hline 1-Hexadecanol & 1.38 & 0.08 & & & \\
\hline \multicolumn{6}{|l|}{ 1-Eicosanol } \\
\hline 1-Tetracosanol & & 1.02 & 0.84 & & 0.61 \\
\hline Bicyclo3.1.0 hexan-3-ol & & & \multicolumn{3}{|c|}{0.17} \\
\hline Esters & 1.02 & 0.82 & 0.3 & 0.41 & 0.42 \\
\hline Allyl nonanoate & 1.02 & 0.24 & & & \\
\hline Isopropyl Myristate & & 0.18 & 0.30 & 0.26 & 0.25 \\
\hline Tetradecenylacetate & & & & & \\
\hline Ethenyl dodecanoate & & 0.39 & & & 0.17 \\
\hline Di-n-octyl phthalate & & & & 0.15 & \\
\hline
\end{tabular}


Furthermore, the result revealed that the hydrocarbon comprising the liquid product had the ratio of alkane/alkene equals to 0.56 , suggesting that the hydrogenation of double bond occurs less frequently in the $\mathrm{NiMo} / \mathrm{NH}_{2}$ - MS catalytic hydrotreatment, as opposed to NiMo/MS. This is possibly due to the limiting interaction between feed molecules and the active center of metal due to the presence of amine group. Therefore, the hydrogenation of double bond occurs less frequently and the reaction is drawn to be located at oxygenated functional group.

Another distinct difference in the liquid product produced by $\mathrm{NiMo} / \mathrm{MS}$ and $\mathrm{NiMo} / \mathrm{NH}_{2}-$ MS is seen from the selectivity of gasoline $\left(\mathrm{C}_{5}\right.$ $\left.\mathrm{C}_{11}\right)$ and diesel hydrocarbon fractions $\left(\mathrm{C}_{12}-\mathrm{C}_{22}\right)$ (Table 3). While the non-functionalized Ni$\mathrm{Mo} / \mathrm{MS}$ favored a prominent selectivity towards diesel fraction, the addition of amine conversely shifted the selectivity into the generation of gasoline-range hydrocarbons. The surface of bimetallic NiMo was reported to be oxophilic, due to the oxygen vacant site provided by $\mathrm{MoO}_{\mathrm{x}}$ during a sequential reduction [21]. The oxophilic surface conducts a strong interaction with oxygenated functional group like carboxylic ac$\mathrm{id}$, which induces the cleavage of $\mathrm{C}-\mathrm{O}$ bond and catalyzes dehydration reaction $[45,46]$. In this pathway, the removal of oxygen from oxygenated group is released in the form of water, which is referred as hydrodeoxygenation mechanism. The feed molecule does not undergo a loss of carbon atom during this mechanism, thus generating longer hydrocarbon chains that are classified in diesel range.

On the other hand, as stated previously, the addition of amine group may cause a hindrance in the interaction between feed molecule and the active center of metal. Therefore, the ox-

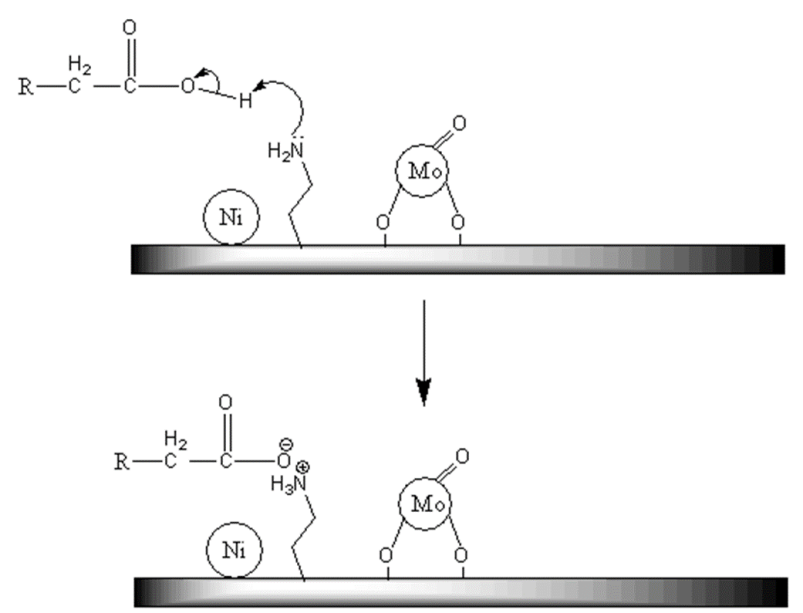

Figure 8. Proposed mechanism of FFA sequestration. ophilic surface of bimetallic NiMo may not serve as effectively in catalyzing hydrodeoxygenation reaction. In contrast, according to a previous study, amine functionalized mesoporous silica was found to favor decarboxylation route [6]. During FFA sequestration, the fatty acid is likely to dissociate into free carboxylate ion by transferring its proton into the base surface of amine group. Through this process, an adsorption is possible due to the interaction between the resulting anionic carboxylate group and the cationic quaternary ammonium. The process is illustrated in Figure 8.

The production of carboxylate ion induces the removal carbon dioxide through electron delocalization that leads to the cleavage of $\mathrm{C}-\mathrm{C}$ bond $[47,48]$. This drives the hydrogenation reaction to occur at the carbanion sites which was produced from the release of $\mathrm{CO}_{2}$. With the loss of one carbon in decarboxylation pathway, the resulting hydrocarbon generated by $\mathrm{Ni}$ $\mathrm{Mo} / \mathrm{NH}_{2}-\mathrm{MS}$ will obviously have shorter chain which falls in the gasoline region. This may be the possible reason to the increase of gasoline selectivity by the use of amine functionalized $\mathrm{NiMo} / \mathrm{NH}_{2}$-MS. The sequestration of FFA can be confirmed from the FTIR spectra of catalyst that was recovered 30 minutes after the hydrotreatment process started (Figure 9). According to the spectra, it is seen that NiMo$\mathrm{NH}_{2} / \mathrm{MS}$ catalyst exhibit the most prominent vibration band of FFA molecules at wavenumber $1743 \mathrm{~cm}^{-1}$ from the asymmetric vibration of $\mathrm{C}=\mathrm{O}$ bond, suggesting more sequestration of the molecule. The new bands appeared at $1458 \mathrm{~cm}^{-1}, 2924 \mathrm{~cm}^{-1}$, and 2854 $\mathrm{cm}^{-1}$ were each the vibrations of $-\mathrm{CH}_{2}$ bond



Figure 9. FTIR spectra of (a) NiMo/NH2-MS before hydrotreatment, (b) NiMo/MS after hydrotreatment, (c) $\mathrm{NiMo} / \mathrm{NH}_{2}$-MS after hydrotreatment. 
that may come from the FFA captured. From the spectra, the formation of carboxylate ion in catalytic hydrotreatment by $\mathrm{NiMo} / \mathrm{NH}_{2}-\mathrm{MS}$ was also detected at wavenumber $1627 \mathrm{~cm}^{-1}$ which corresponds to the asymmetrical strecthing vibration of COO- [49].

This study also revealed that although amine group is very important in the conversion of used coconut oil into hydrocarbon fuel, the process will not be optimum without the help of the metal active site. It was observed by performing a catalytic activity test using amine functionalized mesoporous silica without the presence of metal $\left(\mathrm{NH}_{2}-\mathrm{MS}\right)$. The liquid product contains $21.6 \mathrm{wt} \%$ of oxygenates, which is a much higher level than what was found in the product of metal loaded amine functionalized mesoporous silica. From the result, the role of each modification can be broken down. This confirms that while amine group plays a key role in feed sequestration, it does not facilitate the conversion reaction. The primary deoxygenation reaction is conducted by the active site of metal.

Finally, we compared the work of mono- and bimetallic amine functionalized mesoporous silica in the conversion of used coconut oil into biofuel. It is seen that while the activity of bimetallic catalyst improves with amine addition, it was not able to perform higher conversion compared to monometallic $\mathrm{Ni} / \mathrm{NH}_{2}-$ MS. The latter was able to produce over 77.9 wt\% liquid conversion comprising 68.8 wt\% hydrocarbon compounds and 7.3 wt $\%$ FFA impurities. The result may be due to a higher success of amine functionalization done in monometallic catalyst. As metal dispersion was poorer in monometallic condition, the catalyst may provide more surface to facilitate the interaction between the amine-containing material and silanol group on the surface of mesoporous silica. To confirm this, an EDX analysis was performed (Figure 10). As expected, it can be seen that the mass percentage of $\mathrm{N}$ atom found in $\mathrm{Ni} / \mathrm{NH}_{2}-\mathrm{MS}$ was higher compared to $\mathrm{NiMo} / \mathrm{NH}_{2}$-MS. In fact, the quantity of $\mathrm{N}$ atom found in the latter was so low that it was not detected throughout the analysis. The data also corresponds to the pore volume reduction in both type of catalyst after functionalization. As shown in Table 1, bimetallic NiMo/ $\mathrm{NH}_{2}$-MS undergoes a less drastic decrease of pore volume $\left(0.18 \mathrm{~cm}^{3} \cdot \mathrm{g}^{-1}\right.$ to $\left.0.14 \mathrm{~cm}^{3} \cdot \mathrm{g}^{-1}\right)$ compared to Ni-NH$/ \mathrm{MS} \quad(0.29$ $\mathrm{cm}^{3} \cdot \mathrm{g}^{-1}$ to $0.08 \mathrm{~cm}^{3} \cdot \mathrm{g}^{-1}$, which suggests lower addition of a mine in the former.

The drastic decrease of pore volume occurred in $\mathrm{Ni} / \mathrm{NH}_{2}$-MS may cause even more limitation to the interaction between an entering feed and the metal surface. During sequential sequestration of feed, the catalyst pore is likely to be more saturated with organics which leaves out an even smaller space for molecules to flow. According to previous research, the pore saturation would restrict the access of atoms other than carboxylate oxygen to the reaction center in $\mathrm{Ni}$ surface [6]. Therefore, the hydrogenation would then occur in the oxygen atom of feed, following hydrodeoxygenation pathway which produces water molecule. This explains the proportional ratio of gasoline (31.91 wt\%) and diesel (28.53 wt\%) hydrocarbon generated by $\mathrm{Ni} / \mathrm{NH}_{2}-\mathrm{MS}$. On the other hand, the presence of Mo in a bimetallic Ni$\mathrm{Mo} / \mathrm{NH}_{2}-\mathrm{MS}$ is shown to generate higher ratio of gasoline fraction compared to $\mathrm{Ni} / \mathrm{NH}_{2}-\mathrm{MS}$. a)

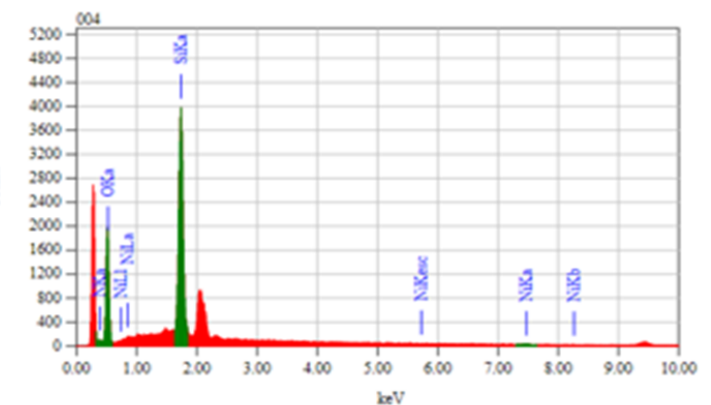

ZAF Method Standardlegs Quantitative Analysig Fitting Coefficient : 0.4975

Element ( $\mathrm{keV}$ ) Mass?

$\begin{array}{lll}\mathrm{N} K & 0.392 & 4.09\end{array}$

O K

Si K

Ni K

Total

38.62

2.23

100.00 b)

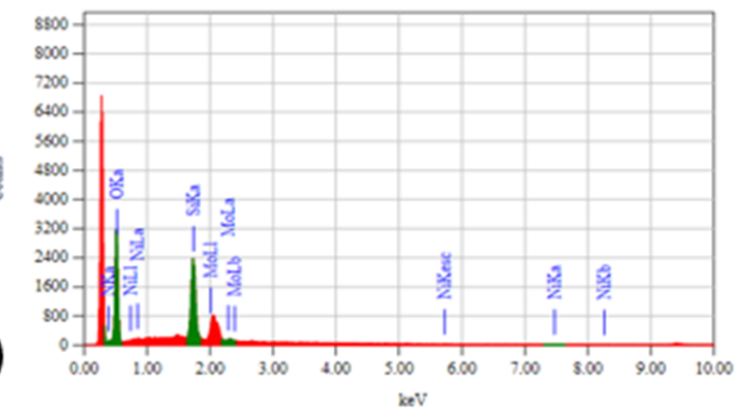

ZAE Method Standardless Quantitative Analysis Fitting Coefficient : 0.6842 Element (keV) Massq

$\mathrm{N} \mathrm{K}$

$\begin{array}{rr}0 & K \\ S i & K\end{array}$

Si K

Mo L-

Total

$\begin{array}{rr}\text { Sigma } & \text { Atom } \\ 0.47 & 83.28 \\ 0.23 & 15.61 \\ 0.21 & 0.40 \\ 0.20 & 0.71\end{array}$

100.00

Figure 10. EDX analysis of (a) $\mathrm{Ni} / \mathrm{NH}_{2}-\mathrm{MS}$ (b) $\mathrm{NiMo} / \mathrm{NH}_{2}-\mathrm{MS}$. 
The lack effectiveness of amine functionalization in bimetallic condition has limited the amount of amine group successfully grafted in the catalyst (Figure 10). Therefore, the decrease of pore volume as well as pore diameter occurs less drastically than in monometallic $\mathrm{Ni} / \mathrm{NH}_{2}-\mathrm{MS}$. This would leave more space in the pore for feed molecules to conduct decarboxylation reaction in the surface of metal.

The generation of $\mathrm{CO}_{2}$ would generally induce the formation of coke, through a previously proposed mechanism [50]. Therefore, catalytic hydrotreatment which predominantly follows decarboxylation pathway would produce higher coke than the others. This is in agreement with the result obtained from the present study. As seen in Table 2, $\mathrm{NiMo} / \mathrm{NH}_{2}-\mathrm{MS}$ catalyst generates more coke $(0.4 \mathrm{wt} \%)$ compared to NiMo/MS (0.03 wt\%) which predominantly undergoes hydrodeoxygenation. The rate of coke formation was also higher in bimetallic $\mathrm{NiMo} / \mathrm{NH}_{2}-\mathrm{MS}$ than in monometallic $\mathrm{Ni} / \mathrm{NH}_{2}$-MS $(0.2 \mathrm{wt} \%)$, due to the restriction of decarboxylation found in the latter catalyst. The catalyst pore of NiMo/MS and $\mathrm{NiMo} / \mathrm{NH}_{2}$-MS was captured by TEM after the hydrotreatment process was carried out (Figure 11). Dark shade was shown to cover the pore of the catalyst, indicating carbon deposition after hydrotreatment. As expected, carbon deposition was shown to occur less vigorously in NiMo/MS than in $\mathrm{NiMo} / \mathrm{NH}_{2}-\mathrm{MS}$.
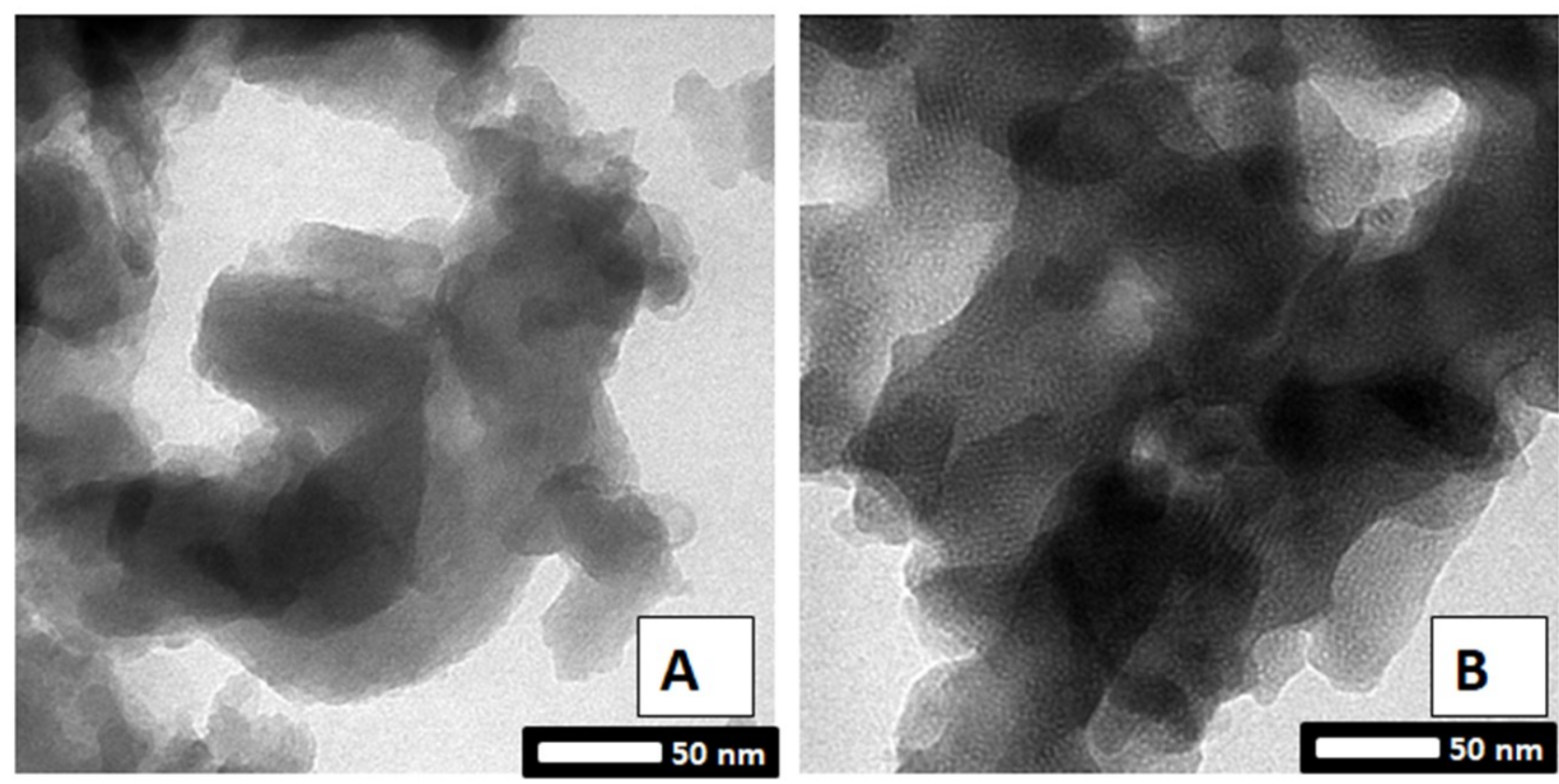

Figure 11. TEM image of pore condition after hydrotreatment (a) NiMo/MS, (b) NiMo/ $\mathrm{NH}_{2}-\mathrm{MS}$. 


\section{Acknowledgments}

Authors would like to thank Universitas Gadjah Mada for the financial support under the scheme of RTA research grant 2019 (Contract Number: 3187/UN1/DITLIT/DITLIT/LT/2019).

\section{Conflict of interest}

The authors declare that they have no conflict to declare.

\section{References}

[1] Huang, D., Zhou, H., Lin, L. (2012). Biodiesel : an Alternative to Conventional Fuel. Energy Procedia, 16, 1874-1885. DOI: 10.1016/j.egypro.2012.01.287.

[2] Vásquez, M.C., Silva, E.E., Castillo, E.F. (2017). Hydrotreatment of vegetable oils: A review of the technologies and its developments for jet biofuel production. Biomass and Bioenergy, 105, 197-206. DOI: 10.1016/j.biombioe.2017.07.008.

[3] Aatola, H., Larmi, M., Sarjovaara, T., Mikkonen, S. (2009). Hydrotreated vegetable Oil (HVO) as a renewable diesel fuel: Tradeoff between NOx, particulate emission, and fuel consumption of a heavy duty engine. $S A E$ Int. J. Engines, 1, 1251-1262. DOI: 10.4271/2008-01-2500.

[4] Hellier, P., Talibi, M., Eveleigh, A., Ladommatos, N. (2018). An overview of the effects of fuel molecular structure on the combustion and emissions characteristics of compression ignition engines. Proc. Inst. Mech. Eng. Part D J. Automob. Eng., 232, 90-105. DOI: 10.1177/0954407016687453.

[5] Yang, Y., Wang, Q., Zhang, X., Wang, L., Li, G. (2013). Hydrotreating of C 18 fatty acids to hydrocarbons on. Fuel Process. Technol., 116, 165-174. DOI: 10.1016/j.fuproc.2013.05.008.

[6] Kandel, K., Frederickson, C., Smith, E.A., Lee, Y.J., Slowing, I.I. (2013). Bifunctional adsorbent-catalytic nanoparticles for the refining of renewable feedstocks. ACS Catal., 3, 2750-2758. DOI: 10.1021/cs4008039.

[7] Pham., L.J. (2016). Industrial Oil Crops. Illinois: Elsevier Inc.

[8] Shankar, P., Ahuja, S., Tracchio, A. (2014). Coconut oil: a review, Agro FOOD Ind. Hi Tech. 24. 62-64.

[9] Eyres, L., Eyres, M.F., Chisholm, A., Brown, R.C. (2016). Coconut oil consumption and cardiovascular risk factors in humans. Nutr. Rev., $\quad 74, \quad 267-280$. D O I : 10.1093/nutrit/nuw002.
[10] Herlina, H., Astriyaningsih, E., Windarti, W. S., Nurhayati, N. (2017). Degree of Coconut Oil Rancidity During Recycled Vacuum Frying for Production of Ripe Banana Chips (RBC). J. Agroteknologi, 11, 186-193. DOI: 10.19184/j-agt.v11i02.6527

[11] Kulkarni, M.G., Dalai, A.K. (2006). Waste cooking oil - An economical source for biodiesel: A review. Ind. Eng. Chem. Res., 45, 2901-2913. DOI: 10.1021/ie0510526.

[12] Kon, K., Onodera, W., Takakusagi, S., Shimizu, K.I. (2014). Hydrodeoxygenation of fatty acids and triglycerides by Pt-loaded $\mathrm{Nb}_{2} \mathrm{O}_{5}$ catalysts. Catal. Sci. Technol., 4, 3705-3712. DOI: 10.1039/c4cy00757c.

[13] Murata, K., Liu, Y., Inaba, M., Takahara, I. (2010). Production of synthetic diesel by hydrotreatment of jatropha oils using $\mathrm{Pt}$ Re/H-ZSM-5 catalyst. Energy and Fuels, 24, 2404-2409. DOI: 10.1021/ef901607t.

[14] Wang, H., Yan, S., Salley, S.O., Ng, K.Y.S. (2012). Hydrocarbon Fuels Production from Hydrocracking of Soybean Oil Using Transition Metal Carbides and Nitrides Supported on ZSM-5. Ind. Eng. Chem. Res., 51, 10066-10073. DOI: 10.1021/ie3000776

[15] Liu, Y., Sotelo-Boyás, R., Murata, K., Minowa, T., Sakanishi, K. (2011). Hydrotreatment of vegetable oils to produce bio-hydrogenated diesel and liquefied petroleum gas fuel over catalysts containing sulfided Ni-Mo and solid acids. Energy and Fuels, 25, 4675-4685. DOI : 10.1021/ef200889e.

[16] Zhou, L., Lawal, A. (2015). Evaluation of presulfided $\mathrm{NiMo/Y}-\mathrm{Al}_{2} \mathrm{O}_{3}$ for hydrodeoxygenation of microalgae oil to produce green diesel. Energy and Fuels, 29, 262-272. DOI: 10.1021/ef502258q.

[17] Trisunaryanti, W., Suarsih, E., Triyono, T., Falah, I.I. (2019). Well-dispersed nickel nanoparticles on the external and internal surfaces of SBA-15 for hydrocracking of pyrolyzed a-cellulose. RSC $A d v$., 9, 12301237. DOI: $10.1039 / \mathrm{c} 8 \mathrm{ra09034c.}$

[18] Fang, Z., Shi, D., Lin, N., Li, A., Wu, Q., Wang, Q., Zhao, Y., Feng, C., Jiao, Q., Li, H. (2019). Probing the synergistic effect of Mo on Ni-based catalyst in the hydrogenation of dicyclopentadiene. Appl. Catal. A Gen., 574, 60-70. DOI: 10.1016/j.apcata.2019.01.026.

[19] Kaluža, L., Karban, J., Gulková, D. (2019). Activity and selectivity of $\mathrm{Co}(\mathrm{Ni}) \mathrm{Mo}$ sulfides supported on $\mathrm{MgO}, \mathrm{Al}_{2} \mathrm{O}_{3}, \mathrm{ZrO}_{2}, \mathrm{TiO}_{2}, \mathrm{MCM}$ 41 and activated carbon in parallel hydrodeoxygenation of octanoic acid and hydrodesulfurization of 1-benzothiophene. React. Kinet. Mech. Catal., 127, 887-902. DOI: $10.1007 / \mathrm{s} 11144-019-01620-\mathrm{x}$. 
[20] Subsadsana, M., Khamor, P., Sangdara, P., Suwannasom, P., Ruangviriyachai, C. (2017). Synthesis and catalytic performance of bimetallic NiMo- and NiW-ZSM-5/MCM-41 composites for production of liquid biofuels. $J$. Fuel Chem. Technol., 45, 805-816. DOI: 10.1016/s1872-5813(17)30039-7.

[21] Chen, N., Gong, S., Qian, E.W. (2015). Effect of reduction temperature of $\mathrm{NiMoO}_{3}$-x/SAPO11 on its catalytic activity in hydrodeoxygenation of methyl laurate. Appl. Catal. B Environ., 174-175, 253-263. DOI: 10.1016/j.apcatb.2015.03.011.

[22] Kukushkin, R.G., Bulavchenko, O.A., Kaichev, V.V., Yakovlev, V.A. (2015). Influence of Mo on catalytic activity of Nibased catalysts in hydrodeoxygenation of esters. Appl. Catal. B Environ., 163, 531-538. DOI: $10.1016 /$ j.apcatb.2014.08.001.

[23] Pestman, R., Koster, R.M., Pieterse, J.A.Z., Ponec, V. (1997). Reactions of carboxylic acids on oxides: 1. Selective hydrogenation of acetic acid to acetaldehyde. J. Catal., 168, 255-264. DOI: 10.1006/jcat.1997.1623.

[24] Marsuki, M.F., Trisunaryanti, W., Falah, I.I., Wijaya, K. (2018). Synthesis of Co, Mo, Co-Mo and Mo-Co catalysts, supported on mesoporous silica-alumina for hydrocracking of a-cellulose pyrolysis oil. Orient. J. Chem., 34, 955-962. DOI: 10.13005/ojc/340245.

[25] Trisunaryanti, W., Falah, I.I., Marsuki, M.F. (2017). Synthesis of Mesoporous SilicaAlumina from Lapindo Mud Using Gelatin from Catfish Bone as a Template: Effect of Extracting Temperature on Yield and Characteristic of Gelatin as well as Mesoporous Silica-Alumina. In CEST 2017. CEST2017_00741. Rhodes, Greece: 15th International Conference on Environmental Science and Technology.

[26] Pandya, P.H., Jasra, R.V., Newalkar, B.L., Bhatt, P.N. (2005). Studies on the activity and stability of immobilized a-amylase in ordered mesoporous silicas. Microporous Mesoporous Mater., 77, 67-77. DOI: 10.1016/j.micromeso.2004.08.018.

[27] Malaibari, Z.O., Croiset, E., Amin, A., Epling, W. (2015). Effect of interactions between $\mathrm{Ni}$ and Mo on catalytic properties of a bimetallic $\mathrm{Ni}-\mathrm{Mo} / \mathrm{Al}_{2} \mathrm{O}_{3}$ propane reforming catalyst. Appl. Catal. A Gen., 490, 80-92. DOI: 10.1016/j.apcata.2014.11.002.

[28] Varkolu, M., Velpula, V., Ganji, S., Burri, D.R., Kamaraju, S.R.R. (2015). Ni nanoparticles supported on mesoporous silica (2D, 3D) architectures: highly efficient catalysts for the hydrocyclization of biomassderived levulinic acid. RSC Adv., 5, 5720157210. DOI: 10.1039/c5ra10857h.
[29] Doronin, V.P., Potapenko, O.V., Lipin, P.V., Sorokina, T.P. (2013). Catalytic cracking of vegetable oils and vacuum gas oil. Fuel, 106, 757-765. DOI: 10.1016/j.fuel.2012.11.027.

[30] Khalil, K.M.S. (2007). Cerium modified MCM-41 nanocomposite materials via a nonhydrothermal direct method at room temperature. J. Colloid Interface Sci., 315, 562-568. DOI: 10.1016/j.jcis.2007.07.030.

[31] Huang, L., Chen, X., Li, Q. (2001). Synthesis of microporous molecular sieves by surfactant decomposition. J. Mater. Chem., 11, 610-615. DOI: 10.1039/b005770n.

[32] Alothman, Z.A. (2012). A review: Fundamental aspects of silicate mesoporous materials. Materials (Basel)., 5, 2874-2902. DOI: $10.3390 / \mathrm{ma} 5122874$.

[33] Thommes, M., Kaneko, K., Neimark, A.V., Olivier, J.P., Rodriguez-Reinoso, F., Rouquerol, J., Sing, K.S.W. (2015). Physisorption of gases, with special reference to the evaluation of surface area and pore size distribution (IUPAC Technical Report). Pure Appl. Chem., 87, 1051-1069. DOI: 10.1515/pac-2014-1117.

[34] Morsi, R.E., Morsi, R.E., Mohamed, R.S. (2018). Nanostructured mesoporous silica: influence of the preparation conditions on the physical-surface properties for efficient organic dye uptake. R. Soc. Open Sci., 5, 172021. DOI: $10.1098 /$ rsos.172021.

[35] Lloyd, G.E. (1987). Atomic number and crystallographic contrast images with the SEM : a review of backscattered electron techniques. Mineral. Mag., 51, 3-19.

[36] Lewis, P., Michklethwaite, S., Harrington, J., Dixon, M., Brydson, R., Hondow, N. (2015). Exploring backscattered imaging in low voltage. J. Phys. Conf. Ser., 644, 012019. DOI: $10.1088 / 1742-6596 / 644 / 1 / 012019$.

[37] Sinha, A.K., Anand, M., Rana, B.S., Kumar, R., Farooqui, S.A., Sibi, M.G., Kumar, R., Joshi, R.K. (2013). Development of Hydroprocessing Route to Transportation Fuels from Non-Edible Plant-Oils. Catal. Surv. from Asia, 17, 1-13. DOI: 10.1007/s10563-012-9148-x.

[38] Rogers, K.A., Zheng, Y. (2016). Selective Deoxygenation of Biomass-Derived Bio-oils within Hydrogen-Modest Environments: A Review and New Insights. ChemSusChem, 9, 1750-1772. DOI: $10.1002 /$ cssc.201600144.

[39] Kandel, K., Anderegg, J.W., Nelson, N.C., Chaudhary, U., Slowing, I.I. (2014). Supported iron nanoparticles for the hydrodeoxygenation of microalgal oil to green diesel. J. Catal., 314, 142-148. DOI: 10.1016/j.jcat.2014.04.009. 
[40] Du, H., Li, M., Liu, D., Ren, Y. (2015), Slurryphase hydrocracking of heavy oil and model reactant: effect of dispersed Mo catalyst. Appl. Petrochemical Res., 5, 89-98. DOI: 10.1007/s13203-014-0092-8.

[41] Fang, K., Ren, J., Sun, Y. (2005). Effect of nickel precursors on the performance of Ni/AlMCM-41 catalysts for n-dodecane hydroconversion. J. Mol. Catal. A Chem., 229, 51-58. DOI: 10.1016/j.molcata.2004.10.055.

[42] Lv, X., Chen, J., Tan, Y., Zhang, Y. (2012). Short Communication A highly dispersed nickel supported catalyst for dry reforming of methane. Catalysis Communication, 20, 6-11. DOI: 10.1016/j.catcom.2012.01.002.

[43] Liu, C., Ye, J., Jiang, J., Pan, Y. (2011). Progresses in the Preparation of Coke Resistant Ni-based Catalyst for Steam and $\mathrm{CO}_{2}$ Reforming of Methane. ChemCatChem, 3, 529-541. DOI: 10.1002/cctc.201000358.

[44] Borowiecki, T., Denis, A., Gac, W., Dziembaj, R., Piwowarska, Z., Drozdek, M. (2004). Oxidation-reduction of $\mathrm{Ni} / \mathrm{Al}_{2} \mathrm{O}_{3}$ steam reforming catalysts promoted with Mo. Appl. Catal. A Gen., 274, 259-267. DOI: 10.1016/j.apcata.2004.07.009.

[45] Kumar, P., Maity, S.K., Shee, D. (2019). Hydrodeoxygenation of stearic acid using Mo modified $\mathrm{Ni}$ and Co/alumina catalysts : Effect of calcination temperature. Chem. Eng. Co $m$ m $u$. . $\quad 1-16$. D O I : 10.1080/00986445.2019.1630396.
[46] Robinson, A.M., Hensley, J.E., Medlin, J.W. (2016). Bifunctional Catalysts for Upgrading of Biomass-Derived Oxygenates: A Review. ACS Catal., 6, 5026-5043. DOI: 10.1021/acscatal.6b00923.

[47] Li, Z., Jiang, Y., Yeagley, A.A., Bour, J.P., Liu, L., Chruma, J.J., Fu, Y. (2012). Mechanism of the Pd-catalyzed decarboxylative allylation of a-imino esters: Decarboxylation via free carboxylate ion. Chem. - A Eur. J., 18, 14527-14538. DOI: 10.1002/chem.201201425.

[48] Kluger, R., Howe, G.W., Mundle, S.O.C. (2013). Avoiding $\mathrm{CO}_{2}$ in Catalysis of Decarboxylation. In Advances in Physical Organic Chemistry. Canada: Elsevier Ltd.

[49] Oomens, J., Steill, J.D. (2008). Free carboxylate stretching modes. J. Phys. Chem. A., 112, 3281-3283. DOI: 10.1021/jp801806e.

[50] Istadi, I., Anggoro, D.D., Amin, N.A.S., Ling, D.H.W. (2011). Catalyst deactivation simulation through carbon deposition in carbon dioxide reforming over $\mathrm{Ni} / \mathrm{CaO}-\mathrm{Al}_{2} \mathrm{O}_{3}$ catalyst. Bull. Chem. React. Eng. Catal., 6, 129-136. DOI: 10.9767/bcrec.6.2.1213.129136. 